\title{
Mass Spectrometry in Environmental Toxicology
}

\author{
Ksenia J. Groh ${ }^{\mathrm{ab}}$ and Marc J.-F. Suter ${ }^{\star a c}$
}

\begin{abstract}
In environmental toxicology, mass spectrometry can be applied to evaluate both exposure to chemicals as well as their effects in organisms. Various ultra-trace techniques are employed today to measure pollutants in different environmental compartments. Increasingly, effect-directed analysis is being applied to focus chemical monitoring on sites of ecotoxicological concern. Mass spectrometry is also very instrumental for studying the interactions of chemicals with organisms on the molecular and cellular level, providing new insights into mechanisms of toxicity. In the future, diverse mass spectrometry-based techniques are expected to become even more widely used in this field, contributing to the refinement of currently used environmental risk assessment strategies.
\end{abstract}

Keywords: Aquatic organisms · Ecotoxicology · Effect-directed analysis · Proteomics · Ultra-trace analysis

Environmental research has for a very long time been focusing on acute toxic effects, trying to find sources of contaminants or dealing with accidental exposure. The negative effects of extensive pesticide use, especially DDT, ${ }^{[1]}$ the Seveso incident in 1976, ${ }^{[2]}$ or ten years later the fire in Schweizerhalle ${ }^{[3]}$ made an incredible impact on human awareness of the detrimental effects of heavy pollution and major accidents. It also boosted sales of highresolution mass spectrometers needed to sensitively quantify all dioxin isomers and congeners. Since then it has been recognized that it is important to understand the fate and behavior of anthropogenic contaminants, because the exposure situation in an ecosystem is very complex. Not only is the exposure variable, with accidents being the most extreme case, but effects of chronic exposure to low concentrations have to be considered as well. Perchloroethylene exposure from contaminated drinking water sources is one classical case where human health is directly affected, resulting in

\footnotetext{
${ }^{*}$ Correspondence: Dr. M. J.-F. Suter ${ }^{\mathrm{ac}}$

Tel: +41587655479

E-mail: suter@eawag.ch

aDepartment of Environmental Toxicology

Eawag - Swiss Federal Institute of Aquatic Science and Technology

Ueberlandstrasse 133, CH-8600 Dübendorf

${ }^{\text {b}} \mathrm{ETH}$ Zürich

Department of Chemistry and Applied Biosciences

$\mathrm{CH}-8093$ Zürich

cETH Zürich

Institute of Biogeochemistry and Pollutant Dynamics $\mathrm{CH}-8092$ Zürich
}

cancer. ${ }^{[4]}$ Furthermore, aquatic organisms are rarely challenged with one pollutant alone, but rather with a chemical mixture resulting from wastewater treatment plant (WWTP) effluent discharge, diffuse inputs such as run-off from urban and agricultural surfaces, dry deposition, remobilization from polluted sediments, or even infiltration of contaminated groundwater into surface waters. Accidents play a minor role in this case and exposure is chronic because inflow is continuous. Therefore today's challenge of environmental toxicology is to understand the effects of chemical mixtures in combination with physical and biological stressors. This requires very sensitive and accurate tools in order to be able to determine the composition and dynamics of the chemical cocktail. For this, mass spectrometry today is the method of choice for determining organic trace contaminants at very low concentrations in various environmental compartments.

Depending on the physico-chemical properties of the analytes, different enrichment and separation techniques are used prior to detection. For instance, GC-MS is still the most widely used method for dioxins, PCBs, PAHs and similarly lipophilic pollutants. Analysis of thermo-labile, polar and ionic compounds, including diverse pesticides, personal care products and pharmaceuticals, became accessible with the advent of electrospray ionization in the 1990s.[5] Many studies have been published since then, investigating the fate and behavior of these compounds in various environmental systems such as WWTPs, which are major point sources of contamination if elimination of a particular chemical is incomplete, ${ }^{[6]}$ or sediments and surface waters. ${ }^{[7]}$

As of December 2013, more than 72 million products are listed as being commercially available, of which 300'000 plus are inventoried/regulated substances. ${ }^{[8]}$ This is a huge number of compounds that can potentially end up in the environment and cause adverse effects in wildlife. The situation gets even worse when considering the fact that their microbial transformation products might be biologically active as well. ${ }^{[9]}$ Hence, when trying to link an observed effect to causative agents, be they chemical, physical or even biological, scientists are faced with the problem of finding the needle in a haystack. ${ }^{[10]}$ Two complementary strategies can be applied to determine the exposure situation in a complex environmental matrix, i) highthroughput chemical multi-residue analysis, ${ }^{[11]}$ or ii) biological effects assessment using either in vitro or in vivo assays, ideally followed by identification of the causative chemical agent.

The limitation of the chemical analysis is, as mentioned above, that no unified method exists which would allow analysis of the universe of chemicals with high sensitivity for all different compound classes simultaneously. Hence, depending on the target analyte, different extraction and enrichment techniques will have to be applied, followed by a suitable separation, in order to reduce the complexity of the sample. Recently, we developed a targeted approach to simultaneously determine chemicals from different substance classes (ionic, polar, lipophilic) known to interfere with the gluco- and mineralocorticoid signaling pathway, using a single step multimode solid-phase cartridge. ${ }^{[12]}$

The number of analytes measured with a given mass spectrometric technique directly affects sensitivity, because the more compounds are monitored, the longer the 
cycle time will be and thus the shorter the time spent on acquiring one specific target, resulting in lower sensitivity. Nonetheless, today's high resolution and highly accurate mass spectrometers (orbitraps and time-of-flight instruments), together with novel approaches such as scan-dependent and -independent experiments, open up entirely new possibilities. Moschet et al. for instance showed that using LC coupled to high-resolution MS allows the identification of known pesticides based on their exact mass only, an approach termed suspect screening. ${ }^{[13]}$ In order to reduce cycle times, scan-dependent experiments perform single reaction monitoring (SRM) or MS/MS experiments only when a precursor ion from a target list is found in a full scan, thus reducing the time lost by monitoring uneventful channels in a classical SRM experiment.

One important drawback of any chemical analysis is that all samples will have to be analyzed, and even then their potential to cause adverse effects in organisms is unknown unless ecotoxicological data is available. Biological effects assessment on the other hand will directly identify samples with a positive response in a given in vivo or in vitro assay, allowing the chemical analysis to be focussed on relevant samples only. The caveat here is that unless an integrative whole organism testing is applied, the assay used will only test for the molecular effect it was designed for. For example, the well-known yeast estrogen screen $(\mathrm{YES})^{[14]}$ will provide the information only for estrogen receptor binding (and cytotoxicity, a non-specific side-effect when using cell-based assays). This disregards any disturbance of the steroidogenesis, although this pathway may lead to detrimental estrogen balance-related effects as well. Hence, ecotoxicologists are faced with the challenge of having to select from a multitude of assays covering different molecular and physiological endpoints. In the ToxCast program initiated by the US Environmental Protection Agency, hundreds of chemicals are currently being tested in various biological assays covering diverse molecular and cellular toxicity pathways, in an effort to build decision support tools based on in vitro screening results to help prioritize chemicals for further investigation. ${ }^{[15]}$

The combination of biological assays with chemical analysis is a very powerful tool to reduce the number of samples having to be analyzed, allowing efforts to be focussed on ecotoxicologically significant cases. The procedure has been around in various forms since the 1980s. Effect-Directed Analysis (EDA), the strategy proposed by Werner Brack (Fig. 1), starts with the extraction of an environmental sample and testing of the extract in a biological assay. ${ }^{[16]}$ Active samples are then fractionated and the resulting fractions again assessed for their biological activity. Positive fractions are then chemically analyzed using both target analysis and screening for unknowns to identify the active components in the fraction. A validation of the identified suspects in the biotest with commercially available or synthesized reference standards finishes the procedure that, as one scientist states in a review of the field, unfortunately often leads to disappointment. ${ }^{[17]}$ The reason this approach can fail is that while a multi-residue screening allows the identification of target analytes, identification of an unknown active component poses a remarkable challenge. Both scandependent and scan-independent methods will provide accurate mass information for the precursor and its fragments, but a multitude of chemical formulas can add up to the molecular weight of the precursor ion. For instance, with 10 ppm instrument accuracy, more than 75 sum formulas are possible for a mass around $400 \mathrm{Da} \cdot{ }^{[18]}$ This number goes down if filtering rules are applied, however, the sum formula alone does not define the structure. MS/MS information has to be used to identify functional groups and substructures, followed by validation of the hypothetical structure, by use of reference compounds (if available). Nevertheless, successful identification of the active chemical by EDA has been achieved.

One such example was the identification of estrogenic compounds in WWTP effluents and receiving rivers. In this study we determined concentrations of estrone (E1), estradiol (E2), ethinylestradiol (EE2), and the xenoestrogen nonylphenol (NP) using GC-MS and calculated the corresponding estrogenicity based on their relative potencies assessed in the YES. A good correlation was found between the measured and calculated estrogenicity. ${ }^{[19]}$ In another example, estradiol was identified as predominant estrogen in UK rivers also using the YES.[20] The zebrafish embryo toxicity assay (zFET) has recently

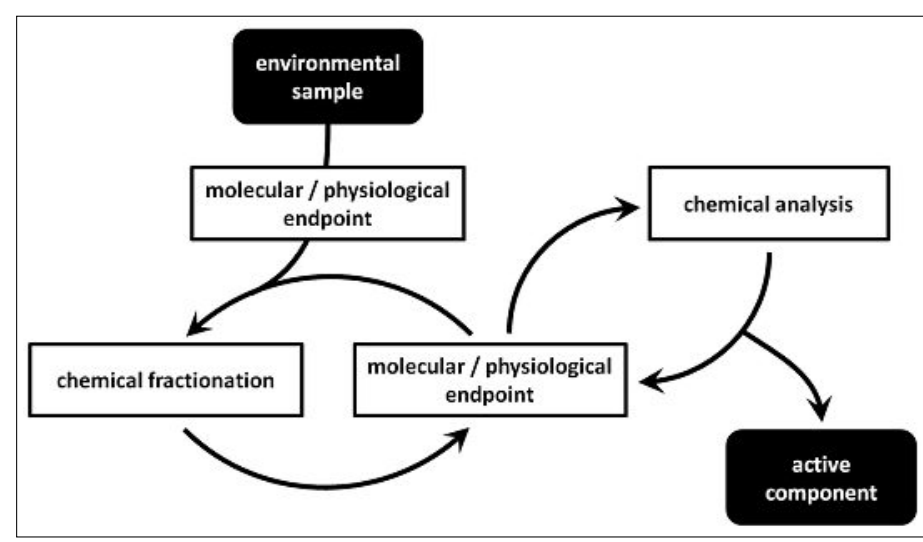

been proposed as a useful alternative to rapidly evaluate whole organism responses to chemical challenge. ${ }^{[21,22]}$ Indeed, using zFET in an EDA of soil samples collected from a former municipal landfill site, a number of previously unknown developmental toxicants were identified. ${ }^{[23]}$

We have also used EDA in an attempt to understand the causes for gonad malformations observed in whitefish (Coregonus sp.) from Lake Thun, Switzerland. ${ }^{[24]}$ For this purpose environmental samples from the food chain (zooplankton) of these fish were taken and investigated for their ability to induce gonadal malformations as well as for their estrogenic potential. In one experiment where whitefish hatchlings from Lake Thun were raised during 3-4 years feeding on the collected zooplankton, evidence was obtained that zooplankton from Lake Thun is the key factor in the development of gonad malformations. ${ }^{[25]}$ Zooplankton extracts also gave a positive signal in the YES, and hence extracts from Lake Thun and the reference Lake Brienz were investigated. This lake is located directly upstream of Lake Thun and has normal incidents of malformations. The samples were separated into 10 fractions on a C18 column. Only fractions 1, 3 and 6 from Lake Thun showed estrogenic activity, while none did from Lake Brienz. ${ }^{[26]}$ In order to rule out the most likely estrogens, all samples were analyzed for their E1, E2, EE2 and NP content using an established LC-MS/MS method, ${ }^{[27]}$ but none contained any traces of these estrogens. In order to identify the unknown estrogenic compound(s), differential scan-dependent MS/MS analyses were performed on the Lake Thun estrogenic fractions and the corresponding fractions from the reference lake. Using this approach, one compound present only in the Lake Thun extract was found, with a protonated molecular ion $[\mathrm{M}+\mathrm{H}]^{+}$of 180.1018 . The associated isotope peaks clearly excluded elements $\mathrm{Cl}$ and Br. With a mass accuracy of 2 ppm, easily achieved on the orbitrap XL (Thermo Scientific) used in this case, and the elements H, C, N, O, F, Si, P, S and I se-
Fig. 1. Schematic representation of effect-directed analysis (EDA) adapted from W. Brack. ${ }^{[16]}$ 
lected, only three candidate sum formulas were possible at this low mass, those being $\mathrm{C}_{10} \mathrm{H}_{14} \mathrm{O}_{2} \mathrm{~N}, \mathrm{C}_{5} \mathrm{H}_{13} \mathrm{O}_{2} \mathrm{~N}_{4} \mathrm{~F}$ and $\mathrm{C}_{7} \mathrm{H}_{16} \mathrm{NF}_{2} \mathrm{Si}$. Since most estrogenic compounds have a phenolic substructure, the latter two were ruled out because of their low ring and double bond equivalents (1.0 and 0.5 respectively).

Assigning a structure to a sum formula is not trivial since it requires some prior knowledge, e.g. structure of the precursor of a transformation product, or substructures from a structure-activity investigation. When starting with a phenolic substructure, one possible candidate is $\mathrm{N}$-acetyltyramine (CAS 1202-66-0). With an estimated $\log \mathrm{K}_{\text {ow }}$ of $1.02^{[28]}$ it would be expected to elute ahead of $\mathrm{E} 2\left(\log \mathrm{K}_{\mathrm{ow}} 4.01\right)$ which ends up in fraction 6 , thus supporting the proposed structure. $\mathrm{N}$-acetyltyramine was then synthesized in-house and tested in the YES. Since it was not estrogenic in the YES, it had to be rejected as potential causative agent for the gonad malformations observed. Nevertheless, the Lake Thun investigation nicely illustrates how EDA helps narrowing down the search for unknown compounds causing adverse effects in the ecosystem.

The EDA approach described above relies on established bioassays measuring specific responses. However, many toxicity pathways, especially those activated through low level chronic exposures, are currently incompletely understood and consequently there are no suitable bioassays available yet. To develop novel biomarkers one strategy is to focus on molecular modes of action. Exposure of organisms to chemical stressors results in the activation of defense mechanisms. When these are overwhelmed, damage of cells and organs ensues as a final manifestation of chemical toxicity. Any cellular and physiological changes observed in response to exposure are accompanied by molecular and biochemical alterations in the organism. Gene transcription rates can be directly affected by various compounds. Such is the case for many endocrine disrupting chemicals that act through binding to nuclear receptors, e.g. estrogen receptor or aryl hydrocarbon receptor, which function as transcription factors regulating the expression of responsive genes. [29-31] Complex interactions can also occur at post-translational level, leading, for example, to a change in the enzyme activity. ${ }^{[32,33]}$ Moreover, some chemicals can also directly interact with cellular constituents and metabolites, thus affecting the biochemical pathways and cellular functions by non-genomic mechanisms. ${ }^{[34-36]}$

During the last decade, diverse '-omics' technologies that allow a high-throughput characterization of gene expression and cellular metabolites, have been developed.
Application of '-omics' in environmental toxicology holds a great promise, because detailed knowledge on the molecular changes induced by chemical exposure may provide valuable insights into the mechanisms of toxicity and support the search for biomarkers of exposure and effects. ${ }^{[37-39]}$

Transcriptomics characterizes the composition and abundance of mRNA transcripts in the specimen. Such analyses are conventionally performed with use of microarray technology and, more recently, by diverse next-generation sequencing-based approaches. ${ }^{[40]}$ Vast amounts of information on the gene expression patterns characteristic of normal development, as well as evolving in response to diverse stressors, have been obtained with use of transcriptomics. ${ }^{[40-43]}$ However, it is the protein and not the transcript, that carries out the cellular functions of a particular gene in most of the cases. Thus, only the information on the protein expression alterations may be regarded as a reliable link between the chemical-induced gene expression changes and perturbed biological functions. Conventionally, mRNA levels have been taken as a proxy for the expression of the corresponding proteins. However, it has been convincingly demonstrated that transcript levels are rather poor indicators of the abundance of the corresponding proteins ${ }^{[44-46]}$ since protein expression can also be regulated on post-transcriptional, translational and post-translational levels. ${ }^{[47,48]}$ Therefore, in order to understand the meaning and significance of gene expression changes induced by pollutants for the overall functioning of the organism under investigation, the information obtained by transcriptomics needs to be complemented by the characterization of the respective proteome. This is addressed by proteomics. ${ }^{[49,50]}$ Going yet one level further, metabolomics deal with characterizing all low-molecular-weight $(<1000$ Da) primary and secondary metabolites found in the organism, which ultimately represent the most 'functional' among all '-omics' targets, since metabolites are the end products of the cellular regulatory processes. ${ }^{[51]}$ Metabolomics data in combination with proteomics may also help to unravel the roles played by the genes with yet unknown functions. ${ }^{[52]}$ Both proteomics and metabolomics analyses largely rely on diverse MS-based approaches. ${ }^{[53,54]}$ Below, we will provide a few specific examples of the diverse MS applications employed in our group in this regard.

Two main approaches to study the proteome can be distinguished, gel-based and gel-free. In the first one, proteins are usually separated and quantified by twodimensional gel electrophoresis (2D-GE), followed by excision of spots of interest and MS-based identification of respective proteins, either intact or through peptides generated by digestion. ${ }^{[55]}$ In an alternative, gel-free, approach, also called shotgun proteomics, proteins are directly digested and the resulting peptides are separated by LC, followed by MS analysis. Peptide separation can be performed either offline or online. We have optimized an online setup, Multidimensional Protein Identification Technology (MudPIT), initially developed for yeast, ${ }^{[56]}$ to study the proteome of zebrafish, a model teleost species. Here, peptides are separated by 2D-LC and directly sprayed into an orbitrap mass spectrometer performing MS/MS analysis.

Using MudPIT to study the proteome of mature zebrafish gonads, much more populated protein lists than those previously delivered by gel-based approaches could be obtained. Several novel protein groups expressed in a sexually dimorphic pattern in zebrafish gonads were identified, ${ }^{[46]}$ demonstrating that global proteome characterization can be a useful source of initial information for defining the molecular pathways in a specific context and for identifying the genes that carry out particular functions. However, one drawback of global proteomics is its general bias towards higher abundance proteins. This happens because in global proteomics one attempts to measure all peptides present in the mixture. Due to the stochastic nature of scan-dependent acquisition, more abundant peptide species generated from higher abundance proteins, are more likely to be selected and analyzed during the run. As a consequence, less abundant peptides are only rarely identified in a particular MudPIT run, and thus low abundance proteins cannot be reliably studied by global profiling. This may limit the application of this technique to the study of molecular mechanisms of toxicity in a complex organism such as zebrafish, since only a small proportion of all the proteins whose expression is altered in response to a stressor would be identified. The interpretation of the results of differential proteomics studies performed with global approaches should be done with caution to avoid misleading conclusions based on the observed variations in high abundance proteins. Many changes commonly observed on the proteome levels could in fact represent only general stress responses, while for the elucidation of toxicant-specific responses the degree of proteome coverage currently delivered by global proteomics may be insufficient. ${ }^{[57,58]}$ Nonetheless, a number of useful insights into the mechanisms of toxicity can be obtained with MudPIT. For example, it was found that exposure to ionic silver and silver nanoparticles (AgNP) induces distinct protein profile changes in zebra-fish em- 
bryos, demonstrating the similarities and differences between the actions of these two toxic agents. [59]

The sensitivity of an MS-based analysis can be improved by using the data acquisition approach aimed at detecting specific proteins of interest, so-called targeted proteomics. ${ }^{[60]}$ SRM, a technique initially developed for ultra-trace chemical analysis, can be adapted to proteomics. Here, only specific fragmentation transitions for chosen peptides representative of targeted proteins are monitored, ${ }^{[61]}$ which allows the sensitivity of MS detection to be enhanced. ${ }^{[62]}$ In this workflow, first a set of proteins to be monitored is selected and proteotypic peptides for each protein are chosen based on global profiling data and/or in silico prediction. SRM conditions for detection of each peptide species can then be optimized either directly for the endogenous peptides or by using synthesized peptides first. The developed SRM protocols are then used to study respective endogenous peptides across different samples. Since SRM analysis typically takes one hour and up to several hundred targets can be monitored within one run in scheduled acquisition mode, this approach allows for much higher throughput compared to MudPIT, where one technical replicate requires up to 22 hours instrument time. The quantification in SRM can be done by using isotopically labeled counterparts for each peptide target.[63] This method, although providing more accurate quantification data, is at the same time more expensive, which may limit its broader application in environmental toxicology research during the initial screening stages in biomarker search projects. We have recently demonstrated that semi-quantitative data can be obtained with SRM by using a few isotopically labeled standards to evaluate MS conditions in different runs and performing a comparison of relative abundance of target proteins across samples by normalizing them to the levels of 'housekeeping' proteins measured in the same run, similar to a normalization approach used for PCRbased mRNA quantification. This setup provides a relatively inexpensive means to perform initial screening of proteins of interest across many different samples obtained from specimens exposed to different chemical concentrations at different time points. Selected proteins demonstrating promising expression patterns, e.g. large changes in response to a particular stressor, can then be studied in more detail and precisely quantified using labeled standards. Using the described semi-quantitative SRM approach, time-resolved profiles of candidate sex-related genes in zebrafish during the period of gonad differentiation were generated. ${ }^{64]}$ As expected, SRM increased the sensitivity of MS detection, allowing several low-abundance proteins unseen during global profiling in adult gonads to be monitored. ${ }^{[46]}$ This allowed the confirmation of protein expression for several genes previously characterized on the mRNA level or by bioinformatic prediction only. For several of the studied proteins, the patterns of protein expression during gonad differentiation confirmed or suggested a possible role in sexual differentiation processes in zebrafish, pinpointing them as candidates for further studies. ${ }^{[64]}$ Currently, targeted proteomics is being used to study the expression of zebrafish proteins potentially responsive to glucocorticoid-like compounds, which may allow identification and establishment of sensitive biomarkers of glucocorticoid exposure for application in EDA of environmental samples.

Even using SRM, several low-abundance proteins of particular interest for sexual differentiation in zebrafish still could not be observed, what was likely due to a very low abundance of these proteins, typically expressed in only a few specific cell types. ${ }^{[64]}$ Monitoring such proteins in the complex samples generated from several organs or whole body extracts indeed presents a serious challenge at the moment. To further improve the detection of such proteins, the complexity of analyzed protein mixtures can be reduced by using diverse fractionation or enrichment techniques. ${ }^{[65]}$ However, such methods are associated with extensive sample processing steps, introducing increased variation between technical replicates and usually requiring increased amounts of starting material, which may present a challenge for ecotoxicological studies. Alternatively, specific cell types where the expression of a protein of interest is expected can be isolated, for example by laser capture microdissection. ${ }^{[66]}$ The latter method, however, still needs further development to establish its compatibility with downstream MS analysis.

A recently developed scan-independent method called SWATH combines the sensitivity of SRM with the screening capabilities of global proteomics. ${ }^{[67]}$ Here, all analytes coming off the LC column are activated and all fragment ions acquired afterwards. This is done by increasing the precursor ion selection window (swath) to e.g. $25 \mathrm{Da}$ instead of typically one for SRM, activating all compounds found in this window, then acquiring all fragments from $400-1200 \mathrm{~m} / \mathrm{z}$. The $25 \mathrm{Da}$ window is then moved to higher mass and the process repeated until the full mass range has been covered. The fragments of a precursor ion are then found by matching their chromatographic profile to the precursor. One very important aspect of this approach is that fragment ions from all precursors are available, because there is no bias caused by thresholds or the stochastic nature of scan-dependent selection of precursors. SWATH data can thus be mined at later times for other compounds that were not in the focus of the initial study! So far, SWATH has been successfully applied to biomarker discovery in clinical research. ${ }^{[68]}$ This technique certainly holds a great potential for environmental research, when applied to both pollutant screening and molecular effects characterization.

The workflows for global proteomics analysis by MudPIT and targeted proteomics analysis by SRM established for zebrafish have been applied to study the proteome of other species relevant for ecotoxicology. The use of global proteomics analysis for studies of stress response mechanisms in unicellular species, such as bacteria, cell lines or green algae, is a particularly promising approach, since in such organisms typically a higher proteome coverage can be obtained as compared to multicellular ones.[50] For example, we have investigated the proteome changes induced by the herbicides paraquat, diuron, and norflurazon in the green alga Chlamydomonas reinhardtii. ${ }^{[69]}$ Here, protein profiles were generated by MudPIT and label-free quantification based on spectral counting in combination with G-test statistics was performed to identify proteins exhibiting significant abundance changes. With this approach, 149-254 differentially expressed proteins could be identified, involved in a variety of metabolic pathways. This work demonstrated that proteome responses to toxicants are more sensitive than the physiological and biochemical endpoints characterized previously, ${ }^{[70]}$ establishing global proteome profiling as a valuable method for studying mechanisms of toxicity in this species. ${ }^{[69]}$ Recently, combined transcriptomics and proteomics analyses have allowed detailed insights into the mechanisms of silver toxicity in $C$. reinhardtii, demonstrating that the initial damage caused by silver through its effects on ATP and photosynthesis, leading to promotion of oxidative stress, is counteracted by the cells through the activation of antioxidant defenses as well as possible elimination of silver via efflux transporters. [71] MudPIT can also be used to obtain precise information on protein synthesis and degradation dynamics. ${ }^{[72]}$ This is done by pulse-labeling with isotopically labeled substrate. It was observed that the time course of diuron-induced degradation of the D1 protein, which is an important photosystem II component, can be accurately followed by performing MudPIT on samples of proteins labeled when algae are growing in ${ }^{15} \mathrm{~N}$-enriched nutrient solution. ${ }^{[73]}$ This method constitutes a valuable addition to label-free quan- 
tification approaches, expanding the array of proteome characterization tools that will advance the research on pollutant toxicity to green algae.

Environmental toxicology has to deal with multiple ecologically relevant species. Presently, the analysis of the proteome of non-sequenced or only partially sequenced species presents a particular challenge. Nonetheless, MudPIT can be applied to obtain the initial proteome characterization in non-target species as well, by using databases from related species. For example, to decipher the mechanisms of acid resistance in frogs, we have studied the proteome in the egg shells of the frog Rana arvalis using the Xenopus laevis (fully sequenced species) database as a reference. ${ }^{[74]}$ Protein sequences deposited in the public databases for a given species are also a useful source of reference information for initial characterization. For the mussel Mytilus galloprovincialis, search against the $\sim 2000$ RefSeq protein sequences deposited for this species allowed identification of over 400 proteins by MudPIT analysis, providing useful initial insights into the cellular pathways affected by the exposure to the biocide tralopyril.[75]

Post-translational modification of proteins plays an important role in determining their overall function and activity. For instance, alterations in glycosylation status of egg-shell proteins seem to be a more important determinant of acid resistance in frog eggs than abundance changes of particular proteins. Diverse approaches exist to study glycosylation and other PTMs with help of MS.[76,77] Currently, some of these methods are being optimized for application in research with ecologically relevant species.

Changes in the concentration of internal metabolites have also proven to be valuable indicators of cellular perturbations induced by pollutants. ${ }^{[51,78-80]}$ Currently, LC- and GC-based approaches are used to study the changes in the $C$. reinhardtii metabolome in response to silver. ${ }^{[81]}$ Metabolomics analysis is expected to be an integral part of investigations aimed at elucidating molecular stress response mechanisms in various species in the future.

MS can also be used to study the direct interaction between pollutants and their cellular targets. For example, matrixassisted laser desorption/ionization timeof-flight (MALDI) MS has been used to characterize the interaction of $\mathrm{Cd}$ with the rainbow trout estrogen receptor, ${ }^{[82]}$ and of silver nanoparticles (AgNP) with bacterial proteins. ${ }^{[36]}$ In the latter study, several fragments of the Escherichia coli enzyme tryptophanase (TNase) were found to preferentially bind to AgNP. Identified Ag adducts were found to be characteristic of strong binding to AgNP rather than asso- ciation of the fragments with ionic silver. Since one high-binding protein fragment contained an Arg103 residue, known to be a part of the active site of the enzyme, this observation explained the loss of TNase enzymatic activity upon associating with AgNPs. Thus, MALDI-TOF MS allowed to suggest a probable mechanism for adhesion of proteins to AgNP. ${ }^{[36]}$ Nano-ESI-MS has been applied recently to study the formation of $\mathrm{Pb}$-phytochelatin (PC) and $\mathrm{Zn}$ PC complexes. ${ }^{[35]}$ PCs are metal-binding oligopeptides that are assumed to play a role in metal detoxification by immobilizing the metals, thus preventing their contact with other biomolecules. Metals are known to induce PC synthesis, however, the direct evidence for binding of the inducing metal to PC has been scarce. Using nano-ESI-MS, we could demonstrate the coordination of lead through the thiol and possibly carboxylic groups, confirming the existence of previously postulated $\mathrm{Pb}-\mathrm{PC}$ complexes, ${ }^{[83]}$ as well as the concurrent formation of $\mathrm{Pb}-, \mathrm{Zn}-$ and $\mathrm{Cu}-\mathrm{PC}$ complexes in algae. ${ }^{[35,84]}$

As demonstrated above, diverse MSbased techniques provide versatile tools for the characterization of chemical exposure and effects in environmental toxicology. EDA will undoubtedly be more widely applied in the future, providing a more comprehensive view of the real life exposure situation. Furthermore, the development of systems biology models integrating transcriptomics, proteomic and metabolomics information, as well as data on proteinprotein and chemical-protein interactions, will provide an improved understanding of molecular mechanisms underlying the adverse outcomes resulting from chemical exposure. These advancements will strengthen the current strategies applied in environmental risk assessment to evaluate and predict the hazards and risks posed by chemicals in the environment.

\section{Received: February 4, 2014}

[1] R. Carson, 'Silent Spring', Houghton Mifflin, USA, 1962.

[2] A. Hay, Nature 1979, 281, 521.

[3] W. Giger, Environ. Sci. Pollut. Res. 2009, 16, S98.

[4] W. Giger, E. Molnar-Kubica, B. Environ. Contam. Tox. 1978, 19, 475

[5] D. W. Kolpin, E. T. Furlong, M. T. Meyer, E. M. Thurman, S. D. Zaugg, L. B. Barber, H. T. Buxton, Environ. Sci. Technol. 2002, 36, 1202.

[6] E. L. M. Vermeirssen, M. J.-F. Suter, P. Burkhardt-Holm, Environ. Tox. Chem. 2006, $25,2413$.

[7] S. Grund, E. Higley, R. Schönenberger, M. J.-F. Suter, J. P. Giesy, T. Braunbeck, M. Haecker, H. Hollert, Environ. Sci. Pollut. Res. 2011, 18, 446.

[8] http://www.cas.org/content/counter

[9] D. E. Helbling, J. Hollender, H.-P. E. Kohler, H. Singer, K. Fenner, Environ. Sci. Technol. 2010, $44,6621$.

[10] P. Burkhardt-Holm, W. Giger, H. Guettinger, U. Ochsenbein, A. Peter, K. Scheurer, H. Segner,
E. Staub, M. J.-F. Suter, Environ. Sci. Technol. 2005, 39, 441A.

[11] S. Huntscha, H. P. Singer, C. S. McArdell, C. E. Frank, J. Hollender, J. Chromatogr. A $\mathbf{2 0 1 2 ,}$ $1268,74$.

[12] A. A. Ammann, P. Macikova, K. J. Groh, K. Schirmer, M. J.-F. Suter, Anal. Bioanal. Chem. 2014, submitted.

[13] C. Moschet, A. Piazzoli, H. P. Singer, J. Hollender, Anal. Chem. 2013, 85, 10312.

[14] E. J. Routledge, J. P. Sumpter, Environ. Tox. Chem. 1996, 15, 241.

[15] R. Kavlock, K. Chandler, K. Houck, R. Judson, N. Kleinstreuer, T. Knudsen, M. Martin, S. Padilla, R. Reif, A. Richard, D. Rotroff, N. Sipes, D. Dix, Chem. Res. Toxicol. 2012, 25, 1287.

[16] W. Brack, Anal. Bioanal. Chem. 2003, 337, 397

[17] T. Reemtsma, Anal. Chim. Acta 2001, 426, 279.

[18] T. Kind, O. Fiehn, BMC Bioinformatics 2006, 7, 234

[19] H.-R. Aerni, B. Kobler, B. V. Rutishauser, F. E. Wettstein, R. Fischer, W. Giger, A. Hungerbühler, M. D. Marazuela, A. Peter, R. Schönenberger, A. C. Vögeli, M. J.-F. Suter, R. I. L. Eggen, Anal. Bioanal. Chem. 2004, 378, 688.

[20] K. V. Thomas, M. R. Hurst, P. Matthiessen, M. J. Waldock, Environ. Tox. Chem. 2001, 20, 2165.

[21] D. C. Volz, S. Belanger, M. Embry, S. Padilla, H. Sanderson, K. Schirmer, S. Scholz, D. Villeneuve, Tox. Sci. 2011, 123, 349.

[22] M. Knoebel, F. J. M. Busser, A. Rico-Rico, N. I. Kramer, J. L. M. Hermens, C. Hafner, K. Tanneberger, K. Schirmer, S. Scholz, Environ. Sci. Technol. 2012, 46, 9690.

[23] J. Legler, M. van Vetzen, P. H. Cenijn, C. J. Houtman, M. H. Lamoree, J. W. Wegener, Environ. Sci. Technol. 2011, 45, 8552.

[24] D. Bernet, T. Wahli, C. Küng, H. Segner, Dis. Aquat. Organ. 2004, 61, 137.

[25] D. Bernet, T. Wahli, C. Küng, H. R. Zieri, H. Segner, Aquatic Biology 2013, submitted.

[26] A. C. Vögeli, Ph.D. Thesis ETH Zürich No. 17756, 2008.

[27] E. L. M. Vermeirssen, O. Korner, R. Schonenberger, M. J.-F. Suter, P. BurkhardtHolm, Environ. Sci. Technol. 2005, 39, 8191.

[28] http://www.epa.gov/opptintr/exposure/pubs/ episuitedl.htm

[29] K. Cheshenko, F. Brion, Y. Le Page, N. Hinfray, F. Pakdel, O. Kah, H. Segner, R. I. L. Eggen, Toxicol. Sci. 2007, 96, 255.

[30] A. Liedtke, J. Muncke, K. Ruefenacht, R. I. L. Eggen, Environ. Toxicol. 2008, 23, 59.

[31] J. Muncke, M. Junghans, R. I. L. Eggen, Environ. Toxicol. 2007, 22, 185.

[32] K. Cheshenko, F. Pakdel, H. Segner, O. Kah, R. I. L. Eggen, Gen. Comp. Endocrinol. 2008, 155, 31.

[33] N. Hinfray, K. Cheshenko, S. Ait-Aissa, O Palluel, J.-M. Porcher, F. Pakdel, R. I. L. Eggen, O. Kah, F. Brion, Cybium 2008, 32, 34.

[34] C. H. Johnson, A. D. Patterson, J. R. Idle, F. J. Gonzalez, Annu. Rev. Pharmacol. Toxicol. 2012, 52, 37 .

[35] C. Scheidegger, M. J.-F. Suter, R. Behra, L Sigg, Front. Microbiol. 2012, 3, 1.

[36] N. S. Wigginton, A. De Titta, F. Piccapietra, J. Dobias, V. J. Nesatyy, M. J.-F. Suter, R. BernierLatmani, Environ. Sci. Technol. 2010, 44, 2163.

[37] R. I. L. Eggen, R. Behra, P. Burkhardt-Holm, B. I. Escher, N. Schweigert, Environ. Sci. Technol. 2004, 38, 58A

[38] R. I. L. Eggen, M. J.-F. Suter, J. Toxicol. Environ. Health, A 2007, 70, 1.

[39] N. Garcia-Reyero, E. J. Perkins, Environ. Toxicol. Chem. 2011, 30, 265.

[40] K. Schirmer, B. B. Fischer, D. J. Madureira, S Pillai, Anal. Bioanal. Chem. 2010, 397, 917. 
[41] D. Voelker, C. Vess, M. Tillmann, R. Nagel, G. W. Otto, R. Geisler, K. Schirmer, S. Scholz, Aquat. Tox. 2007, 81, 355.

[42] M. Froehlicher, A. Liedtke, K. Groh, H. LopezSchier, S. C. Neuhauss, H. Segner, R. I. Eggen, Dev. Biol. 2009, 330, 32

[43] J. J. Michaelson, S. Trump, S. Rudzok, C Graebsch, D. J. Madureira, F. Dautel, J. Mai, S. Attinger, K. Schirmer, M. von Bergen, I. Lehmann, A. Beyer, BMC Genomics 2011, 12, 502.

[44] M. P. Washburn, A. Koller, G. Oshiro, R. R. Ulaszek, D. Plouffe, C. Deciu, E. Winzeler, J. R. III Yates, Proc. Natl. Acad. Sci. USA 2003, $100,3107$.

[45] V. Link, L. Carvalho, I. Castanon, P. Stockinger A. Shevchenko, C.-P. Heisenberg, J. Cell Sci. 2006, 119, 2073

[46] K. J. Groh, V. J. Nesatyy, H. Segner, R. I. L. Eggen, M. J.-F. Suter, Fish Physiol. Biochem. 2011, 37, 619 .

[47] B. Pradet-Balade, F. Boulme, H. Beug, E. W. Muellner, J. A. Garcia-Sanz, Trends Biochem. Sci. 2001, 26, 225.

[48] B. Schwanhaeusser, D. Busse, N. Li, G. Dittmar, J. Schuchhardt, J. Wolf, W. Chen, M. Selbach, Nature 2011, 473, 337.

[49] V. J. Nesatyy, M. J.-F. Suter, Environ. Sci. Technol. 2007, 41, 6891 .

[50] K. J. Groh, V. J. Nesatyy, M. J.-F. Suter, in 'Handbook of molecular microbial ecology', Ed. F. J. de Bruijn. Wiley-Blackwell, 2011, vol. 1, p. 605.

[51] J. L. Wolfender, S. Rudaz, Y. H. Choi, H. K. Kim, Curr. Med. Chem. 2013, 20, 1056.

[52] S. Goulitquer, P. Potin, T. Tonon, Mar. Drugs 2012, 10, 849

[53] V. J. Nesatyy, M. J.-F. Suter, Mass Spectrom. Rev. 2008, 27, 556.
[54] S. B. Milne, T. P. Mathews, D. S. Myers, P. T. Ivanova, H. A. Brown, Biochemistry 2013, 52 , 3829.

[55] A. Gorg, W. Weiss, M. J. Dunn, Proteomics 2004, 4, 3665 .

[56] M. P. Washburn, D. Wolters, J. R. III Yates, Nat. Biotechnol. 2001, 19, 242.

[57] J. Petrak, R. Ivanek, O. Toman, R. Cmejla, J. Cmejlova, D. Vyoral, J. Zivny, C. D. Vulpe, Proteomics 2008, 8, 1744.

[58] G. Van Aggelen, G. T. Ankley, W. S. Baldwin, D. W. Bearden, W. H. Benson, J. K. Chipman, T. W. Collette, J. A. Craft, N. D. Denslow, M R. Embry, F. Falciani, S. G. George, C. C. Helbing, P. f. Hoekstra, T. Iguchi, Y. Kagami, I. Katsiadaki, P. Kille, L. Liu, P. G. Lord, T. McIntyre, A. O’Neill, H. Osachoff, E. J. Perkins, E. M. Santos, R. C. Skirrow, J. R. Snape, C. R. Tyler, D. Versteeg, M. R. Viant, D. C. Volz, T. D. Williams, L. Yu, Environ. Health Perspect. 2010, 118,1 .

[59] K. J. Groh, Eawag, personal communication.

[60] B. Domon, R. Aebersold, Science 2006, 312 , 212

61] A. Maiolica, M. A. Juenger, I. Ezkurdia, R. Aebersold, J. Proteomics 2012, 75, 3495.

[62] P. Picotti, B. Bodenmiller, L. N. Mueller, B. Domon, R. Aebersold, Cell 2009, 138, 795.

[63] P. Picotti, R. Aebersold, Nat. Meth. 2012, 9, 555.

[64] K. J. Groh, R. Schoenenberger, R. I. Eggen, H. Segner, M. J.-F. Suter, Gen. Comp. Endocrinol. 2013, 193, 210.

[65] D. Jiang, H. W. Jarrett, W. E. Haskins, J. Chromatogr., A 2009, 1216, 6881.

[66] A. Jorgensen, J. E. Nielsen, J. E. Morthorst, P. Bjerregaard, H. Leffers, Reprod. Biol. Endocrinol. 2009, 7, 97.

[67] L. C. Gillet, P. Navarro, S. Tate, H. Röst, N.
Selevsek, L. Reiter, R. Bonner, R. Aebersold, Mol. Cell. Proteomics 2012, 11, PMID 22261725.

[68] Y. Liu, R. Hüttenhain, B. Collins, R. Aebersold, Expert Rev. Mol. Diagn. 2013, 13, 811.

[69] H. Nestler, K. J. Groh, R. Schoenenberger, R. I. L. Eggen, M. J.-F. Suter, J. Proteomics 2012, 75,5370 .

[70] H. Nestler, K. J. Groh, R. Schoenenberger, R. Behra, K. Schirmer, R. I. L. Eggen, M. J.-F Suter, Aquat. Tox. 2012, 110-111, 214.

[71] S. Pillai, R. Behra, H. Nestler, M. J.-F. Suter, L. Sigg, K. Schirmer, Proc. Natl. Acad. Sci. USA 2014, in press

[72] T. Muehlhaus, J. Weiss, D. Hemme, F. Sommer, M. Schroda, Mol. Cell. Proteomics 2011, 10 M110.004739.

[73] D. Stamatelatos, Bachelor Thesis ETH Zürich, 2013.

[74] L. Shu, Eawag, personal communication.

[75] I. B. Oliveira, Eawag, personal communication.

[76] S. Pan, R. Chen, R. Aebersold, T. A. Brentnall, Mol. Cell. Proteomics 2011, 10, R110.003251.

[77] N. L. Young, M. D. Plazas-Mayorca, B. A. Garcia, Expert Rev. Proteomics 2010, 7, 79.

[78] N. S. Taylor, R. J. Weber, T. A. White, M. R. Viant, Toxicol. Sci. 2010, 118, 307.

[79] M. R. Viant, Mol. Biosyst. 2008, 4, 980.

[80] L. Mirbahai, A. D. Southam, U. Sommer, T. D. Williams, J. P. Bignell, B. P. Lyons, M. R. Viant, J. K. Chipman, J. Proteome Res. 2013, $12,2895$.

[81] N. Lamari, Eawag, personal communication.

[82] V. J. Nesatyy, B. V. Rutishauser, R. I. L. Eggen, M. J.-F. Suter, Analyst 2005, 130, 1087.

[83] C. Scheidegger, L. Sigg, R. Behra, Environ. Toxicol. Chem. 2011, 30, 2546.

[84] C. Scheidegger, R. Behra, L. Sigg, Aquat. Toxicol. 2011, 101, 423. 